\title{
Coordinating a Supply Chain with Customer Returns and Two-Period Newsboy Problem Using Insurance Contract
}

\author{
Shahrokh Hematyar and Kamal Chaharsooghi, Member, IACSIT
}

\begin{abstract}
For improving the operation of supply chain it is necessary to use coordination mechanisms. This paper investigates the subject of coordination in two-level supply chain using contracts mechanism. By applying contractual relationships among members of a supply chain, double marginalization can be eliminated. We consider a supply chain consisting of one manufacturer and one retailer. A stochastic and two-periodic demand is considered. For obtaining more conformation of model with real conditions, it is assumed that the retailer is faced with return of goods from customer. We determine contractual parameters for achieving the coordination. Modeling and determination of parameters will be done in such a way that win-win condition is provided for both members of supply chain. We compare insurance contract with revenue sharing contract. We find that the expected profit of the supplier with insurance contract will be improved in compared with the revenue sharing contract.
\end{abstract}

Index Terms-Coordination, insurance contract, supply chain management, two-period demand.

\section{INTRODUCTION}

The sellers of products such as apparel, toy, electronics and semiconductors industry are usually faced by rapid product obsolescence, significant price declines over the product life cycle, and high demand uncertainty. For example Korean manufacturers of cellular phones introduce more than 50 new models each year, and the average life cycle of cellular phones in Korea is less than 10 months [1]. As competitors introduce new products into market, it is observed that demand for old products tends to decrease and manufacturer is forced to decline wholesale prices. The anticipation of decreased future prices can cause an incentive for sellers to delay purchases rather than face the prospect of buying high and selling low.

With the increase of product variety, customers feel much uncertain about whether specific items fit their needs or match their tastes. If the items do not fit, the customers may return them. The volume of returns in North America is significant and growing: Chen and Bell [2] reported that "returned goods are estimated to exceed $\$ 100$ billion per year in the United States and in many categories, the number of returns is growing at better than 50\% a year." Mostard [3] stated that return rates of certain fashion items have been estimated to be as high as $74 \%$. Returns can also be a costly item for the supply chain. Biderman reported that Wall-Mart alone processes about $\$ 6$ billion annually in returns [4].

Manuscript received January 10, 2014; revised March 16, 2014.

Shahrokh Hematyar is with the Department of Industrial Engineering Payame Noor University, Tehran, Iran (e-mail: hematyar_sh@yahoo.com).

Kamal Chaharsooghi is with the Department of Industrial Engineering, Tarbiat Modaress University, Tehran, Iran (e-mail: skch@modaes.ac.ir).
Returns also present a serious obsolescence problem for products with sort life cycle where unsold inventory must be discarded or resold in secondary market.

High demand uncertainty and product return leads retailers to reduce their order quantities. On the other hand, suppliers try to induce retailer to purchase and stock greater quantities of products at an early stage. In such environments, Conflicting objectives among players cause double marginalization take place and leads to an inefficient supply chain. Hence, some coordination mechanism is necessary utilizing which may motivate the members to achieve coordination [5].

Supply chain contract is a set of many clauses that offers suitable information and incentive mechanism to guarantee all SC members to achieve coordination and optimize the SC performance. By applying contractual relationships among members of a supply chain double marginalization can be eliminated. As a result optimal output of a supply chain can be obtained. Therefore supply chain contracts allow three main objectives to be achieved: (i) to increase the total supply chain profit so as to make it closer to the profit resulting from a centralized control and (ii) to share the risks among the SC partners (iii) every SC actor obtains a profit higher than he/she would do without contract [6].

In this paper, we propose an insurance contract for two-level supply chain in a two-period newsboy problem. The contract includes two parameters. The first is the side payment from the retailer to the supplier for sharing the risk of overstock. The second is the retailer's share of risk generated form overstock. Share the risk of overstock, which encourages the retailer to order additional stock.

The rest of this paper is organized as follows. In the next section, we review the related literature. Section III introduces the model assumptions and notations and centralized channel as benchmark case. In Section IV we analysis proposed insurance contract. Section V we compare the insurance contract with revenue sharing contract. In Section VI, we present the conclusions and managerial implication of insurance contract.

\section{RELATED RESEARCH}

This paper is closely related to and supply chain contract and customer returns.

Supply chain contract literature can be classified in two main categories. The first focuses on replenishment policies and detailed contract parameters for a given type of contract [7]. Typically, literature in the first category mainly stands at the point of buyers; more specifically, optimizes the buyer's procurement strategy, however, with very little regard to objectives of sellers. The Second category concentrates on 
choosing the terms of the contract so as to achieve supply chain coordination. Examples include [2], [8], [9]. The objective of literature in this category is to choose contracts and their parameters so as to allow each party's optimal decisions to lead to the whole supply chain's optimal performance. Our paper falls into the second category. Next we review related literature in details in the second category.

Detailed reviews of SC contracts and their performance in the original newsboy problem are given [10]-[13]. The most of supply chain contracts that have been discussed by researchers are as follow:

The simplest and the most common contracts are whole sale contracts or price-only contracts. This contract widely used in many industries, but results in double marginalization problem [14]. Buy back contract are used in many industries, especially for products with short life cycles such as books, CDs and computer. By buy back contract is allowed to return any leftover units to the supplier at the end of the period [15], [16]. Pasternack is the first to analyze buyback contracts. He shows supply chain can be coordinated by partial return with full buyback credit or full returns with partial buyback credit [17]. Quantity flexibility (QF) contracts are used mostly in electronics and computer industry. By this contract buyer is allowed to modify the order within limits agreed to the supplier as demand visibility increases closer to the point of sale. By Revenue sharing contract the supplier charges the buyer a wholesale price and buyer shares a fraction of the revenues generated from the sales at the end of period. Revenue sharing contracts are widely used especially in video rental industries and e-commerce business. Cachon and Lariviere intensively discussed a revenue sharing contract in single newsboy problem and compared this situation with other types of contracts [8]. Other contracts that can be used to regulate the relationship among the supply chain's members and improve supply chain performance such as quantity discount [18], sales rebate [19].

The literature review found that the existing research on supply chain contracts focuses mainly on single period newsvendor. However, in reality, selling season may experience different random demands. In such a scenario, the decision maker should design corresponding decisions by using segmental models. Barnes establishes sufficient conditions for channel coordination to be achieved by using a two period correlated demand model [20]. Lee and Lim consider the multi period models with multiple return levels, and show that the new method provides less risk and higher expected profit [21]. Petruzzi and Dada study an integrated firm's behavior when the firm has to decide the retail price and the stocking quantity at the same time for multiple periods [22]. However neither of these studies considered coordination.

Lee et al. examined price protection in a two -period newsboy problem with a single retailer and a single manufacturer. They showed that channel coordination is achieved by choosing the price protection credit properly in the single buying opportunity model. However, they don't discuss the issue win-win [23]. Lineh and Hong study channel coordination with revenue sharing contract for a two period newsboy problem between a single retailer and a single wholesaler. They show a revenue sharing contract can achieves channel coordination [1].
Different functions of customer returns policy have been highlighted in recent years. Moorthy showed that generous return policy helps to signal high quality [3]. Chen and Bell showed that customer return policy affect the firm's pricing and inventory decisions [2]. Ferguson proposed a target rebate contract to reduce customer returns through motivating the retailer to increase sales effort by offering the retailer a specific dollar amount for each unit of false failure returns below a target rate [24]. Chen et al. proposed an buyback contract for a decentralized supply chain that consists of a manufacturer and a retailer. They show that this contract along with profit sharing agreement can achieve perfect supply chain coordination and be win-win for both manufacturer and retailer [2]. Xiao et al. design a buyback/markdown money contract to coordinate the supply chain consisting of one manufacturer under partial refund policy where the retailer faces stochastic demand and consumer return. They found the refund amount and variance of consumer's valuation play an important in the decisions and profitability of the players [25]. Huang et al. introduce a quantity discount contract which specifies a payment to the retailer with an amount exponentially decreasing in the number of returns. They prove that the contract is Pareto improving [26].

Most research on supply chain contract in a two period newsboy problem only consider unsold inventory resulting from demand uncertainty and also the best of author's knowledge no one uses insurance contract as a tool for supply chain coordination. In view of this gap in the literature, there are three main contributions in this paper: first, we integrate customer returns policy within two-period newsboy model in a supply chain. Second, we propose an insurance contract to coordinate supply chain. Third, we compare the insurance contract with revenue sharing contract.

\section{THE MOdEL AsSUMPTION AND CENTRALIZED SUPPLY CHAIN}

\section{A. Model Assumption}

The two-period newsboy problem setting discussed in this paper resembles the one describes in lee [23]. In this model, supply chain consists of a supplier and a single retailer, who supplier produces a product and sells it through a retailer $(\mathrm{R})$. The supplier produces the product at a constant unit cost of $\$ c$ and sells it $W$. Market demand for the product during a selling season, is random variable with probability density function and cumulative density function. The supplier, knowing the characteristics of demand, need to decide contract format and parameters to achieve the best performance so entire supply chain. The retailer is in a competitive market and retail price is fixed by market force. New products are introduced to market at the beginning of the second period; therefore the retail price and the wholesale price of the product decline in the second period. The retailer incurs indirect cost (handling, administration, etc.) in selling the product. The retailer must keep any leftover inventory at the end of the first period, which has an associated holding cost. A lost sales cost is charged for unsatisfied demand. The leftover inventory held by the retailer at the end of the second is salvaged. 
Given the returns policy of the retailer, customers will first attempt to purchase the product and then decide whether to return it after learning their own valuations. We assume that customers return the products with probability $G$ and returned products cannot be resold in the selling period. We would expect returned products from customers to have a lower value than unsold inventory. To avoid triviality, we assume that

1) $0<c_{1}<w<p_{1}$ and $0<h_{1}, 0 \leq g_{2} \leq g_{1},-\left(g_{2}+h_{2}\right)<p_{2}<p_{1}$

2) $c_{1}, w, p_{i}, \hat{c}_{i}, g_{i}, h_{i}, F_{i}(\varepsilon)$ are exogenous

3) $F_{i}(\varepsilon)>0$ for its support $[0, \infty)$

4) The order set up cost is negligible.

5) There is infinite capacity at the supplier and the profits of supplier increases with increases in order quantity.

The definitions required to describe the supply chain, and related parameters, are listed below;

$p_{i}$ retail price per unit in period $i$

$W$ wholesale price per unit in first period

$c_{1}$ wholesaler's marginal cost per unit in period 1

$\hat{c}_{i}$ retailer's indirect cost per unit in period $i$

$g_{i}$ retailer shortage cost per unit in period $i$

$h_{i}$ retailer holding cost per unit in period $i$

$0 \leq h_{1} \leq h_{2}$ and $p_{2}(1-G) \leq h_{2}$

$\varepsilon_{i}$ non-negative random variable denoting demand in period $i$

$F_{i}(\varepsilon)$ distribution function of demand in period $i$

$Q$ order quantity by retailer at the beginning of period 1

$y$ the left over stock at the beginning of period 2

$\pi_{k, i}$ expected profit each member's channel in period I where $k=\{s c$ : total supply chain, $s$ : supplier, $r$ : retailer $\}$

Our objective in this paper is to develop an appropriate insurance mechanism that can achieve channel coordination between the wholesaler and retailer that retailer faces to decline of product values during the product life cycle and customer return. The overstock cost is shared between the wholesaler and retailer at a certain fixed ratio. We say channel coordination is achieved if we can determine an optimal ratio that can induce the retailer to follow the channel's optimal policy, and make both parties better off. Under this frame work, we study the situation where products have long delivery lead time relative to their life cycles, and the retailer has only one opportunity to order at the beginning of the first period.

\section{B. Centralized Channel}

We first characterize the optimal decision to the centralized supply chain. At the end of period 1 , if the leftover stock is $y$, the centralized system expected profit $\pi_{s c-2}(y)$ in the second period is given by

$$
\begin{aligned}
& \pi_{s c-2}(y)=-g_{2} \mu_{2}+\left(p_{2}(1-G)+g_{2}-\hat{c}_{2}\right) y- \\
& \int_{0}^{y}\left[p_{2}(1-G)+g_{2}+h_{2}\right)\left(y-\varepsilon_{2}\right) f\left(\varepsilon_{2}\right) d \varepsilon_{2}
\end{aligned}
$$

Moving back to the first period, the expected profit to integrated company when she order $Q$ is given by

$$
\begin{aligned}
& \pi_{s c-1}(Q)=-\left(c_{1}+\hat{c}_{1}\right) Q++\int_{Q}^{\infty}\left[p_{1}(1-G) Q-g_{1}\left(\varepsilon_{1}-Q\right)\right] f\left(\varepsilon_{2}\right) d \varepsilon_{2} \\
& \int_{0}^{Q}\left[p_{1}(1-G) \varepsilon_{1}-h_{1}\left(Q-\varepsilon_{1}\right)+\pi_{s c-2}\left(Q-\varepsilon_{1}\right)\right] f\left(\varepsilon_{1}\right) d \varepsilon_{1} \\
& =\left(p_{1}(1-G)+g_{1}-c_{1}-\hat{c}_{1}\right) Q-\left(p_{1}(1-G)+h_{1}+g_{1}\right) \int_{0}^{Q}\left(Q-\varepsilon_{1}\right) d \varepsilon_{1}- \\
& g_{1} \mu_{1}+\int_{0}^{Q} \pi_{s c-2}\left(Q-\varepsilon_{1}\right) f\left(\varepsilon_{1}\right) d \varepsilon_{1}
\end{aligned}
$$

for the integrated supply chain, from (2) we obtain the optimal order quantity

$$
\begin{aligned}
& \frac{\partial \pi_{s c-1}(Q)}{\partial Q}=\left(p_{1}(1-G)+g_{1}-c_{1}-\hat{c}_{1}\right)- \\
& {\left[p_{1}(1-G)+g_{1}+h_{1}-\left(p_{2}(1-G)+g_{2}-\hat{c}_{2}\right)\right] F_{1}(Q)} \\
& -\left(p_{2}(1-G)+g_{2}+h_{2}\right) F_{3}(Q)=0
\end{aligned}
$$

where $F_{3}(Q)$ is the distribution function of $\varepsilon_{1}+\varepsilon_{2}=\varepsilon_{3}$

Let $Q_{s c}^{*}$ be the $Q$ that satisfies equation (3). Applying equation (3) to (2), we have the expected profit to the integrated company as follows:

$$
\begin{aligned}
& \pi_{s c-1}\left(Q_{s c}^{*}\right)=-g_{1} \mu_{1}-g_{2} \mu_{2} \\
& +\left[p_{1}(1-G)+g_{1}+h_{1}-\left(p_{2}(1-G)+g_{2}-\hat{c}_{2}\right)\right]\left[Q_{s c}^{*} F_{1}\left(Q_{s c}^{*}\right)-\int_{0}^{Q_{s c}^{*}} F_{1}\left(\varepsilon_{1}\right) d \varepsilon_{1}\right] \\
& +\left[\left(p_{2}(1-G)+g_{2}+h_{2}\right)\left(Q_{s c}^{*} F_{3}\left(Q_{s c}^{*}\right)-\int_{0}^{Q_{c}^{*}} F_{3}(\varepsilon) d \varepsilon_{3}\right)\right]
\end{aligned}
$$

\section{THE DECENTRALIZED SUPPLy CHAIN}

A supply chain involves managing various resources such as inventory, money and information between disparate but dependent chain members. The conflicting objectives and lack of coordination between supply chains may often cause uncertainties in supply chain. The centralized control of supply chain assures coordination but it may not be realistic, whereas in decentralized control, supply chain members optimize local decisions without considering the impact of their decisions on the other member's performance and overall performance of supply chain. Hence, some coordination mechanism is necessary utilizing which may motivate the members to achieve coordination. In the rest of this part, we model problem with insurance contract in section B and revenue sharing contract in Section C.

\section{A. Decentralized Supply Chain with Noinsurance Contrat}

In the decentralized case, the supplier's expected profit is given by

$$
\pi_{s}=\left(w-c_{1}\right) Q
$$

The retailer's expected profit in the second period starting with the leftover stock $y$ is

$$
\begin{aligned}
& \pi_{r, 2}(y)=g_{2} \int_{y}^{\infty}\left(\varepsilon_{2}-y\right) f\left(\varepsilon_{2}\right) d \varepsilon_{2}+ \\
& \left(p_{2}(1-G)-\hat{c}_{2}\right) y-\left(p_{2}(1-G)+h_{2}\right) \int_{0}^{y}\left(y-\varepsilon_{2}\right) f\left(\varepsilon_{2}\right) d \varepsilon_{2}
\end{aligned}
$$


Then, the first period expected profit to the retailer is given by

$$
\begin{aligned}
& \pi_{r, 1}(Q)= \\
& \left(p_{1}(1-G)-\hat{c}_{1}-w\right) Q-\left(p_{1}(1-G)+h_{1}\right) \int_{0}^{Q}\left(Q-\varepsilon_{1}\right) f\left(\varepsilon_{1}\right) d \varepsilon_{1}- \\
& g_{1} \int_{Q}^{\infty}\left(\varepsilon_{1}-Q\right) f\left(\varepsilon_{1}\right) d \varepsilon_{1}+\int_{0}^{Q} \pi_{r, 2}\left(Q-\varepsilon_{1}\right) f\left(\varepsilon_{1}\right) d \varepsilon_{1}
\end{aligned}
$$

The optimal order quantity of retailer is

$$
\begin{aligned}
& \frac{\partial \pi_{r, 1}(Q)}{\partial Q}=\left(p_{1}(1-G)+g_{1}-w-\hat{c}_{1}\right)-\left[\left(p_{1}(1-G)+g_{1}+h_{1}\right)-\right. \\
& \left.\left(p_{2}(1-G)+g_{2}-\widehat{c}_{2}\right)\right] F_{1}(Q) \\
& -\left(p_{2}(1-G)+g_{2}+h_{2}\right) F_{3}(Q)=0
\end{aligned}
$$

Let $Q_{r}^{*}$ be the $Q$ that satisfies (8). The optimal order quantity of the centralized supply chain is higher than that of the decentralized supply chain using a wholesale price contract $Q_{r}^{*} \prec Q_{s c}^{*}$ because $w>c_{1}$.

\section{B. Decentralized Supply Chain with Insurance Contract}

With insurance contract, the supplier shares the risk of overstock with the retailer. Before the selling season, the supplier and retailer agree on an insurance contract with two parameters. The first parameter is the side payment $T$ from the retailer to the supplier. Second parameter $\alpha$ is retailer's share of losses generated by the deviation of his order quantity from the market demand. The supplier's share is $(1-\alpha)$. This insurance contract specifies that the supplier's should share some or all of the retailer's losses, while the retailer gives a premium to the supplier.

Supplier's expected profit with insurance contract is

$$
\begin{gathered}
\left.\pi_{s, i}=\left(w-c_{1}\right) Q+-\left[p_{1}(1-G)+h_{1}\right] \int_{0}^{Q} F_{1}\left(\varepsilon_{1}\right) d \varepsilon_{2}\right\} \\
T-(1-\alpha)\left\{\left[p_{2}(1-G)+h_{2}\right] \int_{0}^{Q} F_{3}\left(\varepsilon_{3}\right) d \varepsilon_{1}\right.
\end{gathered}
$$

With the insurance contract, the retailer's expected profit is

$$
\begin{aligned}
& \pi_{r, 1}=\left(p_{1}(1-G)-\hat{c}_{1}-w_{1}\right) Q- \\
& \alpha\left(p_{1}(1-G)+h_{1}\right) \int_{0}^{Q}\left(Q-\varepsilon_{1}\right) f\left(\varepsilon_{1}\right) d \varepsilon_{1}-g_{1} \int_{Q}^{\infty}\left(\varepsilon_{1}-Q\right) f\left(\varepsilon_{1}\right) d \varepsilon_{1} \\
& +\int_{0}^{Q} \pi_{r, 2}\left(Q-\varepsilon_{1}\right) f\left(\varepsilon_{1}\right) d \varepsilon_{1}-T
\end{aligned}
$$

We acquire the optimal order quantity by the solving the following equation:

$$
\begin{aligned}
& \frac{\partial \pi_{\mathrm{r}, 1}}{\partial \mathrm{Q}}= \\
& \quad\left(p_{1}(1-G)+g_{1}-\hat{c}_{1}-w\right)-\left[\alpha\left(p_{1}(1-G)+h_{1}\right)+g_{1}-\right. \\
& \left.\quad\left(p_{2}(1-G)+g_{2}-\hat{c}_{2}\right)\right] F_{1}(Q)- \\
& \quad\left[\alpha\left(p_{2}(1-G)+h_{2}\right)+g_{2}\right] F_{3}(Q)=0
\end{aligned}
$$

If the wholesale price is an exogenous variable, then the retailer's optimal order quantity with the insurance contract is higher than that with wholesale price contract. They are equal only when $\alpha=1$. Let $Q_{r, i}^{*}$ be the $\mathrm{Q}$ that satisfies equation (11)

$$
\begin{gathered}
\frac{\partial Q_{r, i}^{*}(\alpha)}{\partial \alpha}=-\frac{\left(p_{1}+h_{1}\right) F_{1}(Q)+\left(p_{2}+h_{2}\right) F_{3}(Q)}{\left[\alpha\left(p_{1}+h_{1}\right)+g_{1}-\left(p_{2}+g_{2}-\hat{c}_{2}\right)\right] f_{1}(Q)+s} \prec 0 \\
{\left[\alpha\left(p_{2}+h_{2}\right)+g_{2}\right] f_{3}(Q)=s}
\end{gathered}
$$

Hence, the optimal order quantity of the retailer decreases as $\alpha$ increases.

Let $Q_{s c}^{*}=Q_{r, i}^{*}$ we get

$$
\alpha^{*}=1-\frac{\left(w-c_{1}\right)}{\left[p_{1}(1-G)+h_{1}\right] F_{1}\left(Q_{s c}^{*}\right)+\left[p_{2}(1-G)+h_{2}\right] F_{3}\left(Q_{s c}^{*}\right)}
$$

in this situation, the retailer's order quantity enables the supply chain system to achieve the best performance.

The optimal wholesale price of the supplier is

$$
\begin{aligned}
& W^{*}=\underset{\left.c_{1}<w^{*}<\left[p_{1}+h_{1}\right)\right] F_{1}\left(Q_{s c}^{*}\right)+\left(p_{2}+h_{2}\right) F 3\left(Q_{s c}^{*}\right)}{\arg \max }\left[\left(w-c_{1}\right) Q_{s c}^{*}+T\right. \\
& -(1-\alpha)\left[p_{1}+h_{1}-p_{2}+c_{2}\right] \int_{0}^{Q_{s c}^{*}} F_{1}\left(\varepsilon_{1}\right) d \varepsilon_{1}- \\
& \left.\left(p_{2}+h_{2}\right) \int_{0}^{Q_{s c}^{*}} F_{2}\left(\varepsilon_{2}\right) d \varepsilon_{2}\right]
\end{aligned}
$$

The insurance contract will not be accepted unless each agent's expected profit is better than the reservation expected profit.

Hence, the side payment $(T)$ must satisfy the following conditions:

$$
\begin{aligned}
& \pi_{s, i}\left(Q_{s c}^{*}\right) \geq \pi_{s}\left(Q_{r}^{*}\right) \\
& (1-\alpha)\left\{\left(p_{2}(1-G)+h_{2}\right) \Gamma_{3}\left(Q_{s c}^{*}\right)+\left(p_{1}(1-G)+h_{1}\right) \Gamma_{1}\left(Q_{s c}^{*}\right)\right\}+T \geq \\
& (w-c) Q_{r}^{*}
\end{aligned}
$$

$\pi_{r, i}\left(Q_{s c}^{*}\right) \geq \pi_{r}\left(Q_{r}^{*}\right)$

$\pi_{s c}-(1-\alpha)\left\{\left(p_{2}(1-G)+h_{2}\right) \Gamma_{3}\left(Q_{s c}^{*}\right)+\left(p_{1}(1-G)+h_{1}\right) \Gamma_{1}\left(Q_{s c}^{*}\right)\right\}-T \geq$

$-g_{1} \mu_{1}-g_{2} \mu_{2}$

$+\left[\left(p_{1}(1-G)+g_{1}+h_{1}\right)-\left(p_{2}(1-G)+g_{2}-\widehat{c}_{2}\right)\right] \Gamma_{1}\left(Q_{r}^{*}\right)+$

$\left(p_{2}(1-G)+g_{2}+h_{2}\right) \Gamma_{3}\left(Q_{r}^{*}\right)$

Define $\Gamma_{i}(x)=\int_{0}^{x} x f_{i}(x)$

We get the feasible range of the side payment by solving (13) and (14), which is $\left[T_{\max }, T_{\min }\right]$.

Based on the analysis above, we come up with the following theorem:

Theorem 1. When

$$
\alpha^{*}=1-\frac{\left(w-c_{1}\right)}{\left.\left[p_{1}(1-G)+h_{1}\right)\right] F_{1}\left(Q_{s c}^{*}\right)+\left(p_{2}(1-G)+h_{2}\right) F 3\left(Q_{s c}^{*}\right)}
$$

and $T \in\left[T_{\max }, T_{\min }\right]$, the insurance contract can coordinate the supply chain. The retailer's and the supplier's expected profits are as below:

$\pi_{s, i}=(1-\alpha)\left\{\left(p_{2}(1-G)+h_{2}\right) \Gamma_{3}\left(Q_{s c}^{*}\right)+\left(p_{1}(1-G)+h_{1}\right) \Gamma_{1}\left(Q_{s c}^{*}\right)\right\}+T$

$\pi_{r, i}=\pi_{s c}-T-(1-\alpha)\left\{\left(p_{2}(1-G)+h_{2}\right) \Gamma_{3}\left(Q_{s c}^{*}\right)+\left(p_{1}(1-G)+h_{1}\right) \Gamma_{1}\left(Q_{s c}^{*}\right)\right\}$ 


\section{Decentralized Supply Chain with Revenue Sharing Contract}

Revenue sharing contracts play an important role in the management of supply chains. Revenue sharing contracts are observed in video rental, franchising, online retailing and elsewhere. We compare insurance contract with revenue sharing contract for showing its important characteristics. The revenue sharing can be specified by two parameters: $(\varphi, w)$. By offering revenue sharing contract the supplier reduces the unit wholesale price $w$ to $w^{\prime}\left(w<w^{\prime}\right)$ which is lower than the unit product cost and the retailer shares the fraction $1-\varphi$ of the revenues generated from the sales. In other words, the supplier receives a percentage $1-\varphi$ of the retailer's revenue.

The retailer's expected profit with revenue sharing contract is as below:

$$
\begin{aligned}
& \pi_{r, r v}(Q)=-g_{1} \mu_{1}-g_{2} \mu_{2} \\
& +\left\{\varphi p p_{1}(1-G)+g_{1}-\hat{c}_{1}-w-\left[\left(\varphi p_{1}(1-G)+h_{1}+g_{1}\right)-\right.\right. \\
& \left.\left(\varphi p_{2}(1-G)-\hat{c}_{2}+g_{2}\right)\right] F_{1}(Q)-\left(\left(\varphi p_{2}(1-G)+h_{2}+g_{2}\right) F_{3}(Q)\right\} Q \\
& +\left[\left(\varphi p_{1}(1-G)+h_{1}+g_{1}\right)-\left(\varphi p_{2}(1-G)-\hat{c}_{2}+g_{2}\right)\right] \Gamma_{1}(Q) \\
& +\left(\varphi p_{2}(1-G)+h_{2}+g_{2}\right) \Gamma_{3}(Q)
\end{aligned}
$$

The optimal order quantity of retailer is

$$
\begin{aligned}
& \frac{\partial \pi_{r, 1}(Q)}{\partial Q}= \\
& \left(\phi p_{1}(1-G)+g_{1}-w-\hat{c}_{1}\right)-\left[\left(\phi p_{1}(1-G)+g_{1}+h_{1}\right)-\right. \\
& \left.\left(\phi p_{2}(1-G)+g_{2}-\hat{c}_{2}\right)\right] F_{1}(Q)-\left(\phi p_{2}(1-G)+g_{2}+h_{2}\right) F_{3}(Q)=0
\end{aligned}
$$

Retailer's expected profit with revenue sharing contract is

$$
\begin{aligned}
& \pi_{r, r v}(Q)=-g_{1} \mu_{1}-g_{2} \mu_{2} \\
& +\left[\left(\phi p_{1}(1-G)+h_{1}+g_{1}\right)-\left(\phi p_{2}(1-G)-\hat{c}_{2}+g_{2}\right)\right] \Gamma_{1}(Q) \\
& +\left(\phi p_{2}(1-G)+h_{2}+g_{2}\right) \Gamma_{3}(Q)
\end{aligned}
$$

If $Q_{s c}^{*}=Q_{r, i}^{*}$ then supply chain in a two-period newsboy problem is coordinated while

$$
\begin{aligned}
& w^{*}=c_{1}- \\
& (1-\varphi)(1-G)\left\{p_{1}-\left(p_{1}-p_{2}\right) \int_{0}^{Q_{s c}^{*}} f\left(\varepsilon_{1}\right) d \varepsilon_{1}-p_{2} \int_{0}^{Q_{s c}^{*}} f\left(\varepsilon_{3}\right) d \varepsilon_{3}\right\}
\end{aligned}
$$

If $\pi_{r, r v}(Q)=0$ we can find the value of $\phi$ that minimize retailer's expected profit

$\underline{\varphi}=$

$$
\begin{gathered}
-g_{1} \mu_{1}-g_{2} \mu_{2}+\left[\left(g_{1}+h_{1}\right)-\left(g_{2}-\hat{c}_{2}\right) \int_{0}^{Q_{s c}^{*}} \varepsilon_{1} f\left(\varepsilon_{1}\right) d \varepsilon_{1}+D\right. \\
(1-G)\left(p_{1}-p_{2}\right) \int_{0}^{Q_{s c}^{*}} \varepsilon_{1} f\left(\varepsilon_{1}\right) d \varepsilon_{1}+\left(p_{2}\right) \int_{0}^{Q_{s c}^{*}} \varepsilon_{3} f\left(\varepsilon_{3}\right) d \varepsilon_{3} \\
D=g_{2} \int_{0}^{Q_{s c}^{*}} \varepsilon_{3} f\left(\varepsilon_{3}\right) d \varepsilon_{3}
\end{gathered}
$$

The supplier's and the retailer's expected profit functions with revenue sharing are respectively,

$$
\begin{aligned}
& \pi_{r}\left(Q_{s c}^{*}\right)= \\
& -g_{1} \mu_{1}-g_{2} \mu_{2}+\left(\phi p_{2}(1-G)+g_{2}+h_{2}\right) \int_{0}^{Q_{s c}^{*}} \varepsilon_{3} f\left(\varepsilon_{3}\right) d \varepsilon_{3} \\
& {\left[\varphi p_{1}(1-G)+g_{1}+h_{1}-\left(\phi p_{2}(1-G)+g_{2}-\hat{c}_{2}\right)\right] \int_{0}^{Q_{s c}^{*}} \varepsilon_{1} f\left(\varepsilon_{1}\right) d \varepsilon_{1}} \\
& \pi_{s}\left(Q_{s c}^{*}\right)=(1-\phi)(1-G)\left\{\left(p_{1}-p_{2}\right) \int_{0}^{Q_{s c}^{*}} \varepsilon_{1} f\left(\varepsilon_{1}\right) d \varepsilon_{1}+\right\}
\end{aligned}
$$

Theorem 2. For any revenue sharing contract $(\varphi, w)$ base on equations (18) and (19), we can find a series of insurance contract $(T, \alpha)$ that coordinate supply chain and generate the same expected profit for each member of supply chain in a situation that market demand is equal. $(T)$ and $(\alpha)$ satisfy $\alpha \in[0,1] \quad A=p_{1} \Gamma_{1}\left(Q_{s c}^{*}\right)+p_{2} \Gamma_{3}\left(Q_{s c}^{*}\right)$ $T=(\alpha-\phi) A-\left((1-\phi) p_{2}(1-G)+(1-\alpha) h_{1}\right) \Gamma_{1}\left(Q_{s c}^{*}\right)-(1-\alpha) h_{2} \Gamma_{3}\left(Q_{s c}^{*}\right)$

With the insurance contract

$$
\begin{aligned}
& \pi_{r, i}\left(Q_{s c}^{*}\right)=\pi_{s c}-T \\
& +(\alpha-1)\left\{\left(p_{2}(1-G)+h_{2}\right) \Gamma_{3}\left(Q_{s c}^{*}\right)+\left(p_{1}(1-G)+h_{1}\right) \Gamma_{1}\left(Q_{s c}^{*}\right)\right\} \\
& \pi_{s, i}\left(Q_{s c}^{*}\right)=T+ \\
& (1-\alpha)\left\{\left(p_{2}(1-G)+h_{2}\right) \Gamma_{3}\left(Q_{s c}^{*}\right)+\left(p_{1}(1-G)+h_{1}\right) \Gamma_{1}\left(Q_{s c}^{*}\right)\right\}
\end{aligned}
$$

D. Comparing Insurance Contract with Revenue Sharing

By comparing the expected profit of supplier and the retailer under insurance contract with the revenue sharing contract, we know that $(T)$ and $(\alpha)$ satisfy following equation

$$
\frac{\pi_{s c}}{(1-\alpha)\left[A+h_{1} \Gamma_{1}\left(Q_{s c}^{*}\right)\right]+T}=\frac{\pi_{s c}}{(1-\varphi)\left[A-p_{2} \Gamma_{1}\left(Q_{s c}^{*}\right)\right]}
$$

By simplifying, we find

$$
T=(\alpha-\varphi) A-\left((1-\varphi)(1-G) p_{2}+(1-\alpha) h_{1}\right) \Gamma_{1}\left(Q_{s c}^{*}\right)
$$

This equation allows us to find a series of insurance contracts $(T, \alpha)$ that generate the same expected profit for each agent for the same market demand.

We can formulate following expressions based on the analysis above:

$$
\begin{gathered}
\pi_{s, r}=(1-\phi)^{2}\left[P_{2}^{2} \operatorname{Var}\left(\Gamma_{1}\left(Q_{s c}^{*}\right)\right)+\operatorname{Var}(A)\right] \\
\pi_{s, i}=(1-\alpha)^{2}\left[h _ { 1 } ^ { 2 } \operatorname { V a r } \left(\Gamma_{1}\left(Q_{s c}^{*}\right)+h_{2}^{2} \operatorname{Var}\left(\Gamma_{2}\left(Q_{s c}^{*}\right)+\operatorname{Var}(A)\right]\right.\right.
\end{gathered}
$$

We find following results by comparing $\alpha=\varphi$.

Only when $\alpha=1$ and $\varphi=1$ then $\alpha=\phi$ is true. This means that the supplier's expected profit with insurance contract is equal to supplier's expected profit with revenue sharing contract.

$$
\alpha \prec \varphi
$$

If $\alpha \prec \varphi$, then $T<0$. This means that the supplier gives a side payment to the retailer and receives a smaller profit with insurance contract than that with the revenue sharing contract. The variance of the supplier's profit with insurance contract is higher than revenue sharing contract. Because

$$
F_{3}(x) \leq F_{1}(x) \leq 1 \text { and } \operatorname{Var}_{3}(x) \leq \operatorname{Var}_{1}(x), \forall x \geq 0
$$




$$
\begin{aligned}
& p_{2}(1-G) \leq h_{2} \text { and } 0 \leq h_{1} \leq h_{2} \\
& \operatorname{Var}\left(\Gamma _ { 1 } \left(Q_{s c}^{*}\left[p_{2}(1-G)\right]^{2} \leq\left[h _ { 1 } ^ { 2 } \operatorname { V a r } \left(\Gamma _ { 1 } \left(Q_{s c}^{*}+h_{2}^{2} \operatorname{Var}\left(\Gamma 3\left(Q_{s c}^{*}\right)\right]\right.\right.\right.\right.\right. \\
& \alpha \succ \varphi
\end{aligned}
$$

If $\alpha \succ \varphi$, then $T>0$ this means that the retailer gives a side payment to the supplier and supplier receives a higher profit with insurance contract than the revenue sharing contract. If $\alpha \rightarrow 1, \varphi \rightarrow 0$ variance of the supplier's profit with insurance contract is smaller than that revenue sharing contract.

\section{MANAGERIAL IMPLICATION AND CONCLUSION}

The financial effects of insurance contract on the retailer, manufacturer, and total chain over two period time horizon are described in Table I.

TABLE I: BENEFITS AND COSTS OF INSURANCE CONTRACT

\begin{tabular}{cccc}
\hline \hline & retailer & manufacture & Total chain \\
\hline Incremental sales & $\begin{array}{c}\text { Incremental sales } \\
\text { receive a fixed } \\
\text { payment at the first } \\
\text { Incur only Partly of } \\
\text { overstock cost }\end{array}$ & $\begin{array}{c}\text { Incremental } \\
\text { sales }\end{array}$ \\
\hline $\begin{array}{c}\text { Incur a fixed } \\
\text { payment for using } \\
\text { an insurance }\end{array}$ & $\begin{array}{c}\text { Incur only Partly } \\
\text { of overstock cost }\end{array}$ & \\
\hline \hline
\end{tabular}

The manufacture benefits by the incremental sales to the retailer. Since $Q_{s c}^{*}>Q_{r}^{*}$ the manufacture will particularly benefit if its margins are decreasing over time.

Since retailer's price drops sharply in the second period consequently, retailer margin is decreasing over time, then incurring partly of unsold units cost by supplier has positive effect on the retailer's profit. On the other hand the retailer incurs a premium to supplier under insurance contract

We find the following results by comparing the revenue sharing and price protection with insurance contract:

1) The expected and variance of the supplier's profit with insurance contract will be improved in compared with the revenue sharing if $\alpha \prec \varphi$. Therefore, the manufacturer prefers to choose insurance contract when variation of demand is high.

2) We find that there exists a range of profit share $(T)$ $T \in\left[T_{\max }, T_{\min }\right]$ for which the insurance contract is win-win for both the supplier and retailer: both are better off with the agreement than without it, and both share the additional profits that accrue through supply chain coordination meanwhile revenue sharing contract does not have this

\begin{tabular}{|c|c|c|c|c|c|c|}
\hline & & & \multicolumn{2}{|c|}{ Insurance contract } & \multicolumn{2}{|c|}{ Revenue sharing } \\
\hline & & & $\mathrm{R}$ & $\mathrm{S}$ & $\mathrm{R}$ & $\mathrm{S}$ \\
\hline \multirow{4}{*}{$\begin{array}{l}\text { First } \\
\text { Period }\end{array}$} & \multirow{2}{*}{ Revenue } & $\mathrm{F}$ & & & & \\
\hline & & $\mathrm{V}$ & & & & \\
\hline & \multirow{2}{*}{$\operatorname{cost}$} & $\mathrm{F}$ & & & & \\
\hline & & $\mathrm{V}$ & & & & \\
\hline \multirow{4}{*}{$\begin{array}{l}\text { Second } \\
\text { period }\end{array}$} & \multirow{2}{*}{ Revenue } & $\mathrm{F}$ & & & & \\
\hline & & $\mathrm{V}$ & & & & \\
\hline & \multirow{2}{*}{$\operatorname{cost}$} & $\mathrm{F}$ & & & & \\
\hline & & $\mathrm{V}$ & & & & \\
\hline
\end{tabular}
characteristic.

TABLE II: COMPARING CONTRACT

3) The other limitation of revenue sharing contract is that may reduce the enthusiasm of retailer for selling products, since $w=c$ meanwhile the retailer has more enthusiasm for selling products because the retailer has paid a fixed amount at the first period under insurance contract.

4) The statues of revenue and cost of insurance contract on the retailer and supplier over two period time horizon are described in Table II. One of limitations is that the supplier earns no revenue in the second period under insurance contract unlike revenue sharing contract.

\section{Numerical Examples}

In this section, a numerical test is performed to validate the results of the theory analysis. We use the parameter value in lee [23], which are as follows:

$$
\begin{gathered}
p_{1}=100, p_{2}=62, g_{1}=50, g_{2}=31, h=0, v=23,{ }_{1}=65.5 \\
c_{2}=50.8, \hat{c}_{1}=0, \hat{c}_{2}=0, h_{2}=23 \varepsilon_{1} \sim N(40,50), \varepsilon_{2} \sim N(60,150)
\end{gathered}
$$

The range for side payment is determined based on inequalities (13), (14). For the numerical example, the range for $\mathrm{T}$ is between $[536,674]$. The constraint in inequality (14) gives an optimum value of $\alpha=.91$

Optimal order quantity of supply chain is $Q_{S c}^{*}=89.9$

Optimal order quantity of retailer is $Q_{r}^{*}=82.9$ that is less than the optimal order quantity of supply chain.

The expected profit supply chain and retailer and supplier are presented in Table III.

TABLE III: EXPECTED PROFIT FOR NUMERICAL EXAMPLE

\begin{tabular}{llll}
\hline \hline & Supply chain & retailer & Supplier \\
\hline Coordination & 2882.932 & 1680.882 & 1202.05 \\
Non coordination & 2744.562 & 1542.512 & 1202.05 \\
\hline \hline
\end{tabular}

It can be observed from Fig. 1, the expected profit of supplier increases with increase in side payment $T$.

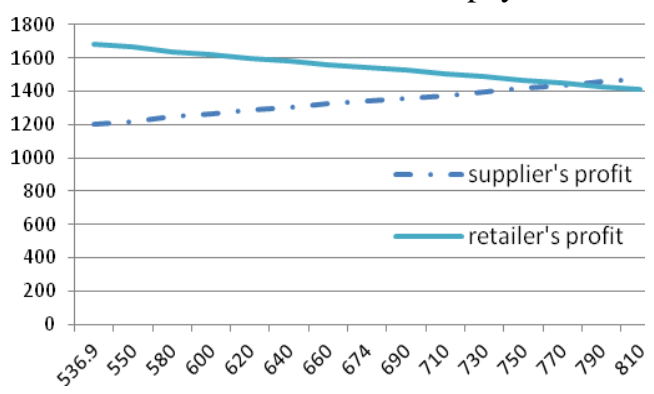

Fig. 1. Effects of T on the agent's expected profit.

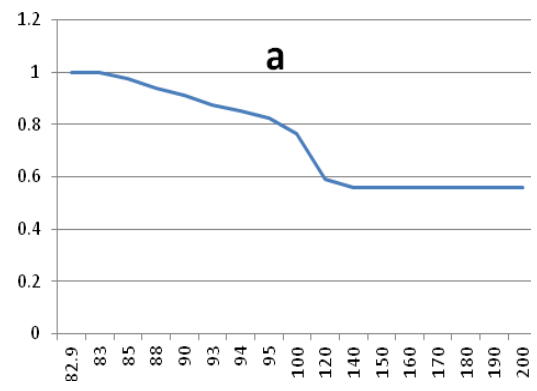

Fig. 2. Effects of $\alpha$ on the optimal order quantity.

Fig. 2 shows the effects of $\alpha$ on order quantity of retailer. When $\alpha$ increases the order quantity of retailer decreases. Fig. 2 shows and confirms that a smaller $\alpha$ reduces the retailer's risk and motivates him to order additional product. In other 
word, higher $\alpha$ means a higher risk and a higher possibility of losses for the retailer. This situation induces the retailer to order smaller consequently, to receive a less expected profit. In addition, there is always a value of $\alpha$ that enables the retailer's optimal order quantity to be equal to the supply chain system's optimal order quantity.

Fig. 3 shows when the wholesale price decrease, the retailer's optimal order quantity increases with the same value of $\alpha$.

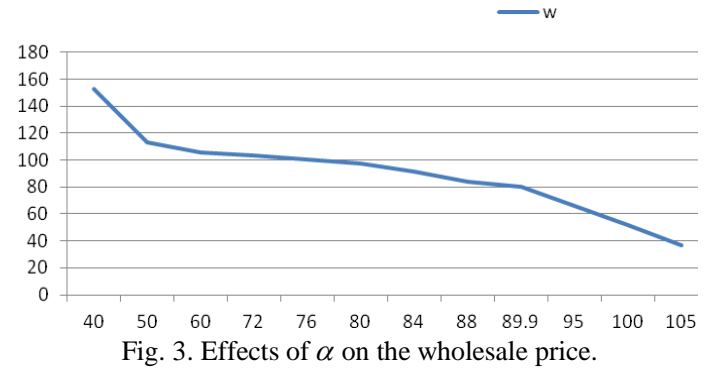

Fig. 4 shows the effects of $\alpha$ on total profit of supply chain. This figure shows that the supply chain expected profit function is a concave function with respect to $\alpha$. The value of $\alpha$ that maximizes the supply chain expected profit is 0.91 .

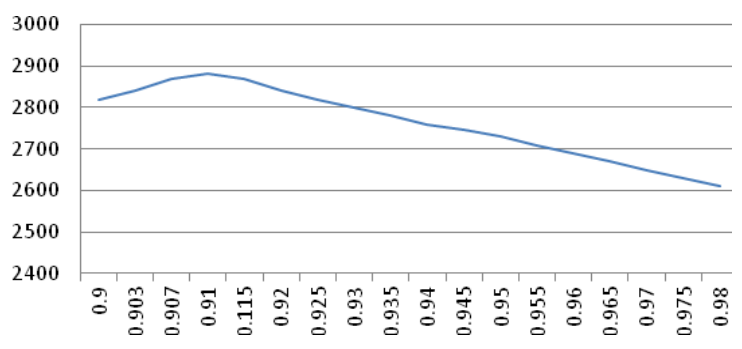

Fig. 4. Effect of $\alpha$ on the supply chain total expected profit.

Fig. 5 shows when side payment $T$ increases with the same value of $\alpha$, the value of $\varphi$ parameter related to revenue sharing contract decreases.

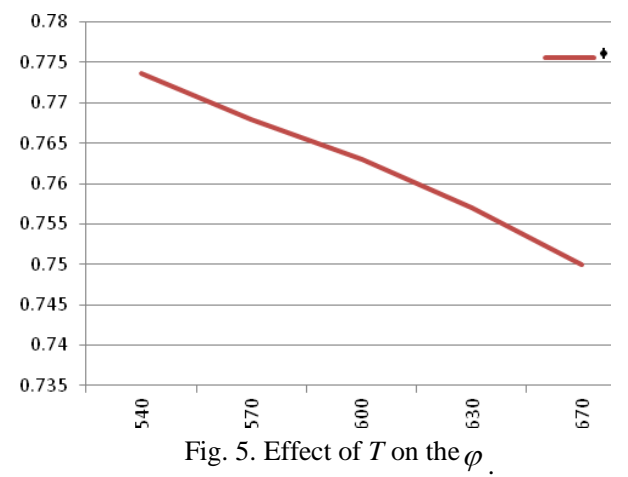

\section{CONCLUSION}

In this paper, we study coordination of a two-echelon supply chain consisting of one manufacture and one retailer in a two period newsboy problem. Retailer determines order quantity while experiencing customer returns and stochastic demand. With the increase of product variety, customers feel much uncertain about whether specific items fit their needs or match their tastes. If the items do not fit, the customers may return them. Due to introduce new product into market, retailer faces drastic declines of product value during the product life cycle. High demand uncertainty and returned products leads retailer to reduce order quantity. We propose an insurance contract that includes two parameters. We show that insurance contract could coordinate the supply chain and desirable for both chain members. We compare the insurance contract with revenue sharing contract. We find the expected profit of the supplier with insurance contract will be improved in compared with the revenue sharing contract and one of limitations is that supplier earns no revenue in the second period under insurance contract.

\section{REFERENCES}

[1] C. T. Linh and Y. Hong, "Channel coordination through a revenue sharing contract in a two-period newsboy problem," European Journal of Operational Research, vol. 198, pp. 822-829, 2009.

[2] J. Chen and P. C. Bell, "Coordinating a decentralized supply chain with customer returns and price-dependent stochastic demand using a buyback policy," European Journal of Operational Research, vol. 212, pp. 293-300, 2011.

[3] S. Moorty, "Managing channel profits: Comment," Marketing Science, vol. 6, pp. 375-379, 1987.

[4] D. Biderman, "Many happy returns," Journal of Commerce, vol. 5, pp. $1-3,2005$.

[5] G. Huang and L. Liu, "Supply chain decision making and coordination under price dependent demand," Journal of Systems Science and Systems Engineering, vol. 15, pp. 330-339, 2006.

[6] B. C. Giri, S. Bardhan, and T. Maiti, "Coordinating a two-echelon supply chain through different contracts under price and promotional effort-dependent demand," Journal of Systems Science and Systems Engineering, vol. 22, pp. 295-318, 2013.

[7] H. Xiong, B. Chen, and J. Xie, "A composite contract based on buy back and quantity flexibility contacts," European Journal of Operational Research, vol. 210, pp. 559 -567, 2010.

[8] G. P. Cachon and M. A. Lariviere, "Supply chain coordination with revenue sharing: Strengths and limitations," Management Science, vol. 51, pp. 30-44, 2005.

[9] S. Saha, "Supply chain coordination through rebate induced contracts," Transportation Resarch Part E, vol. 50, pp. 120-137.

[10] A. A. Tsay, "Quantity-Flexibility contract and supplier-costumer incentives,” Management Science, vol. 45, pp. 1339-1358, 1999.

[11] M. Albrechat, Supply chain coordination mechanisms: New Aprroach for collaborative planning, lecture notes in economics and mathematical systems, Springer-Verlag Berlin Heidelberg, 2010.

[12] M. I. Hohn, Relational supply contracts, lecture notes in economics and mathematical systems, Springer-Verlag Berlin Heidelberg, 2010.

[13] G. P. Cachon, "Supply chain coordination with contracts," Handbooks in Operation Research and Management Science, vol. 11, pp. 227-339, 2003.

[14] H. Yong, Z. Xuan, and Z. Lindu, "Coordinating a study supply chain with effort dependent stochastic demand," Applied Mathematical Modeling, vol. 33, pp. 2777-2790, 2009.

[15] H. Emmons and S. Gilbert, "The role of returns policies in pricing and inventory decisions for catalogue goods," Management Science, vol. 44, pp. 276-283, 1998.

[16] K. L. Donohue, "Efficient supply contract for fashion goods with forecast updating and two production modes," Management Science, vol. 46, pp. 1397-1411, 2000.

[17] B. Pasternak, "Optimal pricing and returns policies for perishable commodities," Marketing Science, vol. 4, pp. 166-176.

[18] B. Tomlin, "Capacity investments in supply chains: sharing the gain rather than sharing the pain," Manufacturing and Service Operation Management, vol. 45, pp. 1339-1385, 2003.

[19] T. A. Taylor, "Supply chain coordination under channel rebates with sales effort effects," Management Science, vol. 48, pp. 992-1007, 2002.

[20] D. Barnes, Y. Bassok, and R. Anupindi, "Coordination and flexibility in supply contracts with options," Manufacturing and Services Operations Management, vol. 4, pp. 171-207, 2002.

[21] C. H. Lee and J. I. Lim, "Designing a supply chain coordinating returns policies for a risk sensitive manufacturer," International Journal of Management Science, vol. 11, pp. 1-17, 2005.

[22] N. C. Petruzzi and M. Dada, "Pricing and the newsvendor problem: A review with extensions," Operational Research, vol. 47, pp. 183-194, 1999. 
[23] H. Lee, V. Padmanabhan, T. A. Taylor, and S. Whang, "Price protection in the personal computer industry," Management Science, vol. 45, pp. 633-642, 2000.

[24] M. Ferguson, J. R. M. Guide, and G. C. Souza, "Supply chain coordination for false failure returns," Manufacturing \& Service Operations Management, vol. 8, pp. 376-393, 2006.

[25] T. Xiao, K. Shi, and D. Yang, "Coordination of a supply chain with consumer return under demand uncertainty," International Journal of Production Economics, vol. 124, pp. 171-180, 2010.

[26] X. Huang, S. M. Choi, W. K. Ching, T. K. Siu, and M. Huang, "On supply chain coordination for false failure returns: A quantity discount contract approach," International Journal of Production Economics, vol. 133, pp. 634-644, 2011.

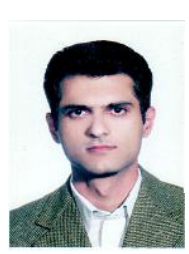

Shahrokh Hematyar was born in 1975, Tehran province, Iran country. $\mathrm{He}$ is a $\mathrm{PhD}$ student in the Department of Industrial Engineering, Payame Noor University, Tehran, Iran. His principle research interests focus on supply chain coordination. Some of his publications have appeared in IEEE Xplore database, www.doaj.com and Shahrif Journal of Industrial Engineering and Management. He works in MAPNA CO. His expertise is about supply chain coordination and quality assurance. He has published several papers in international conferences.

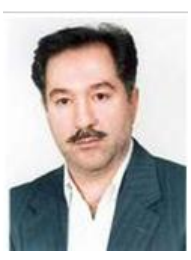

Kamal Chaharsooghi is an associate professor of Industrial Engineering at the Department of I.E., Faculty of Engineering, Tarbiat Modares University, Tehran, Iran. His research interests include manufacturing systems, supply chain management. Dr. Chaharsooghi obtained his PhD from Hull University, England. Dr. Chaharsoogh's work has appeared in European Journal of Operational Research, International Journal of Advanced Manufacturing Technology, Scientia Iranica, Modares Journal of Engineering, Amirkabir Journal of Science and Technology, International Journal of Engineering Science. 